\title{
ANALISA MANAJEMEN RISIKO K3 DALAM INDUSTRI MANUFAKTUR DI INDONESIA: LITERATURE REVIEW
}

\author{
Irfan Muhammad ${ }^{1}$, Indri Hapsari Susilowati ${ }^{2}$ \\ Magister Keselamatan dan Kesehatan Kerja ${ }^{1}$, Departemen Keselamatan dan Kesehatan Kerja ${ }^{2}$ \\ Fakultas Kesehatan Masyarakat, Universitas Indonesia \\ irfan.muhammadhse@gmail.com ${ }^{1}$, indri@ ui.ac.id ${ }^{2}$
}

\begin{abstract}
The manufacturing industry is an industry that processes raw materials into semi-finished and finished products. In every production process and work activity in the manufacturing industry, some risks potentially lead to work accidents. In Indonesia, the manufacturing industries have high contributions to work accidents, along with construction industries, amounting to $63.6 \%$ in 2020. Work accidents can occur due to the poor management of Occupational Safety and Health (OSH) risk management in companies. This study aims to provide an overview and analyze hazard identification, risk assessment, and risk control in Indonesia's manufacturing industry..This study is a literature review of published journals related to OSH risk management in Indonesia's manufacturing sector from 2015-2020 obtained from google scholar. The keywords used were "hazard identification", "risk assessment", and "the manufacturing industry". After the selection process was carried out, 26 journals were included in this study.From the literature review, the most identified hazards are physical hazards such as being hit by a press machine, being exposed to a grinding machine, and being pinched by a production machine. In the risk assessment, the level of risk that frequently appears is the medium \& high levels. Risk control widely used is administrative control, such as setting up standard operating procedures, providing guidance in operations, etc. The most identified hazards in The manufacturing industry in Indonesia are physical hazards. The risk levels that frequently appeared were medium \& high levels. And risk control that is widely used is administrative control.
\end{abstract}

\section{Kata kunci $\quad$ : Indonesian Manufacturing Industry, OHS, Risk Management}

\begin{abstract}
ABSTRAK
Industri manufaktur merupakan industri yang mengolah bahan baku menjadi produk setengah jadi maupun produk jadi. Di dalam proses produksi dan aktifitas pekerjaan dalam industri manufaktur memiliki risiko dari bahaya sehingga berpotensi terjadinya kecelakaan kerja. Di Indonesia industri manufaktur memiliki kontribusi yang tinggi dalam kecelakaan kerja bersamaan dengan konstruksi yaitu sebesar $63,6 \%$ tercatat pada tahun 2020. Kecelakaan kerja dapat terjadi salah satunya karena pengelolaan manajemen risiko keselamatan dan kesehatan kerja di perusahaan yang tidak dilaksanakan dengan baik. Penelitian ini bertujuan untuk menganalisis dan memberikan gambaran identifikasi bahaya, penilaian risiko dan pengendalian risiko pada industri manufaktur di Indonesia. Penelitian ini merupakan literature review dimana sumber data diperoleh dari "google scholar" berupa jurnal yang telah di publish. Data penelitian mengenai manajemen risiko keselamatan dan kesehatan kerja pada industri manufaktur di Indonesia dari tahun 2015-2020 dengan keywords identifikasi bahaya, penilaian risiko dan industri manufaktur. Setelah dilakukan proses penyeleksian didapatkan sebanyak 26 jurnal. Dari kajian literatur ini, bahaya yang paling banyak terdentifikasi adalah bahaya fisika seperti terkena mesin press, terkena mesin gerinda, terjepit mesin produksi, dll. Dalam penilaian risiko di peroleh tingkat risiko yang paling banyak muncul yaitu level medium \& high. Pada pengendalian risiko yang paling banyak digunakan adalah pada pengendalian administratif seperti pembuatan standar operasional prosedur, memberikan bimbingan dalam operasi, dll. Pada industri manufaktur di Indonesia menggambarkan bahaya yang paling banyak terdentifikasi adalah bahaya fisika, di peroleh tingkat risiko yang banyak muncul yaitu pada level medium \& high dan pengendalian risiko yang banyak digunakan adalah pengendalian administratif.
\end{abstract}

Kata Kunci $\quad:$ K3, Industri Manufaktur Indonesia, Manajemen Risiko 


\section{PENDAHULUAN}

Industri manufaktur merupakan industri yang mengolah bahan baku menjadi produk setengah jadi maupun produk jadi (Mangkunegara, 2016). Dan di dalam setiap proses produksi dan aktifitas pekerjaan memiliki risiko dari bahaya yang ada. (Sutriyanto, 2021) dalam tulisannya di Tribunbews.com menjelaskan di Indonesia, dalam dua tahun terakhir, dilaporkan terjadi kenaikan kecelakaan kerja yang signifikan, yaitu naik sebesar $55.2 \%$ dari tahun sebelumnya, yakni sebanyak 114.000 kasus di tahun 2019 menjadi 177.000 kasus di tahun 2020. (Sutriyanto, 2021) pada Tribunbews.com berdasarkan Badan Penyelenggara Jaminan Sosial Nasional (BPJS Kesehatan), kurang lebih setiap harinya sebanyak 12 pekerja di Indonesia mengalami cacat permanen dimana kecelakaan kerja terbesar disumbang oleh sektor manufaktur dan konstruksi sebesar $63,6 \%$, sektor transportasi 9,3\%, sektor kehutanan $3,8 \%$, pertambangan $2.6 \%$ dan sisanya sebesar $20,7 \%$.

Mengutip dari (Sutriyanto, 2021) dalam tulisannya di Tribunbews.com industri manufaktur pada tahun 2020 memiliki kontribusi yang tinggi dalam kecelakaan kerja bersamaan dengan konstruksi yaitu sebesar 63,6\% . Kecelakaan kerja ini sendiri dapat terjadi salah satunya karena pengelolaan manajemen risiko keselamatan dan kesehatan kerja di perusahaan yang tidak dilaksanakan dengan baik (Restuputri Palupi \& Dyah Sari, 2015). Karena menurut (Restuputri Palupi \& Dyah Sari, 2015), salah satu upaya untuk mengurangi atau menghilangkan bahaya yang dapat menyebabkan kecelakaan di tempat kerja yaitu diperlukan suatu manajemen risiko yang kegiatannya meliputi identifikasi bahaya, analisis potensi bahaya, penilaian risiko, pengendalian risiko, serta pemantauan dan evaluasi.

Pada penelitian (AL Bantani et al., 2015), menjelaskan bagaimana mengidentifikasi potensi-potensi bahaya dari aktivitas-aktivitas yang dikerjakan, menganalisa risiko bahaya yang ada di setiap kegiatan operasional dan melakukan pengendalian bahaya dengan nilai risiko bahaya tertinggi dengan menggunakan job safety analysis (JSA) dalam industri manufaktur pembuatan kapal. Pada penelitian (Alfatiyah, 2017), dalam industri manufaktur pembuatan plumbing fitting dalam mendukung penerapan sistem manajemen keselamatan dan kesehatan kerja (SMK3) dilakukan metode hazard identitication, risk assessment and risk control di seksi casting untuk mencegah terjadinya kecelakaan kerja. Dari penjelasan kedua penelitian tersebut menjelaskan terkait identifikasi bahaya, analisis potensi bahaya, penilaian risiko dan pengendalian risiko yang termasuk ke dalam kegiatan atau tahapan dalam manajemen risiko (Restuputri Palupi \& Dyah Sari, 2015).

Dengan adanya bahaya yang dapat berdampak kepada kecelakaan kerja pada industri manufaktur di Indonesia, maka penelitian literature review ini bertujuan untuk menganalisis dan memberikan gambaran identifikasi bahaya, penilaian risiko dan pengendalian risiko dari setiap pekerjaan dalam industri manufaktur di Indonesia, sehingga dapat dilakukan pengendalian untuk melindungi tenaga kerja dari kecelakaan kerja

\section{METODE}

Penelitian ini merupakan literature review, dimana sumber data dalam penelitian ini berasal dari literatur berupa jurnal nasional yang telah di publish yang di peroleh dari search engine "google scholar". Data penelitian ini mengenai manajemen risiko pada keselamatan dan kesehatan kerja dalam industri manufaktur di Indonesia dari tahun 2015-2020 dengan kata kunci "identifikasi bahaya, penilaian risiko dan industri manufaktur" dan didapatkan sebanyak 461 penelitian yang kemudian data tersebut dilakukan filter kembali berdasarkan kesesuaian judul, abstrak dan isi yang sesuai dengan penelitian ini sehingga didapatkan sebanyak 26 jurnal. 
Dan tujuan dari penelitian ini yaitu menganalisis gambaran manajemen risiko keselamatan dan kesehatan kerja dalam industri manufaktur di Indonesia terkait dengan identifikasi bahaya, penilaian risiko dan pengendalian risiko untuk melindungi tenaga kerja dari kecelakaan kerja

\section{HASIL}

Daftar artikel yang terpilih kemudian dianalisis dari aspek identifikasi bahaya seperti yang di tunjukan pada tabel 1 berikut

Tabel 1. Hasil Analisis Identifikasi Bahaya Dalam Industri Manufaktur di Indonesia

\begin{tabular}{lcccc}
\hline \multirow{2}{*}{ Paper Identity } & \multicolumn{5}{c}{ Klasifikasi Bahaya } \\
\cline { 2 - 5 } & Kimia & Fisika & Biologi & Ergo \\
\hline $\begin{array}{l}\text { (Nuryono } \\
\text { Aini, 2020) }\end{array}$ & $\sqrt{ }$ & $\sqrt{ }$ & - & - \\
\hline $\begin{array}{l}\text { (Giananta et al., } \\
\text { 2020) }\end{array}$ & - & $\sqrt{ }$ & - & - \\
\hline $\begin{array}{l}\text { (Tiara \& Herry, } \\
\text { 2020) }\end{array}$ & $\sqrt{ }$ & $\sqrt{ }$ & - & $\sqrt{ }$ \\
\hline $\begin{array}{l}\text { (Mirawati et al., } \\
\text { 2017) }\end{array}$ & $\sqrt{ }$ & $\sqrt{ }$ & - & - \\
\hline $\begin{array}{l}\text { (Ningsih \& Hati, } \\
\text { 2019) }\end{array}$ & - & $\sqrt{ }$ & - & - \\
\hline
\end{tabular}

\begin{tabular}{lllll}
\hline (Ilmi, 2019) & $\sqrt{ }$ & $\sqrt{ }$ & - & - \\
\hline (Saputro, 2019) & $\sqrt{ }$ & $\sqrt{ }$ & - & - \\
\hline (Restuputri & & & & \\
Palupi \& Dyah & $\sqrt{ }$ & $\sqrt{ }$ & - & -
\end{tabular}

\begin{tabular}{lllll} 
Sari, 2015) & & & & \\
\hline (Khasanah \& & & & & \\
Nawawinetu, & $\sqrt{ }$ & $\sqrt{ }$ & & \\
2018) & & & & - \\
\hline $\begin{array}{l}\text { (Santoso et al., } \\
\text { 2016) }\end{array}$ & $\sqrt{ }$ & $\sqrt{ }$ & - & - \\
\hline $\begin{array}{l}\text { (Sutrisno, 2020) } \\
\text { (Fauzan \& }\end{array}$ & - & $\sqrt{ }$ & - & \\
$\begin{array}{l}\text { Puspitasari, } \\
\text { 2019) }\end{array}$ & $\sqrt{ }$ & $\sqrt{ }$ & - & $\sqrt{ }$ \\
\hline $\begin{array}{l}\text { Ramadanita \& } \\
\text { Rusmiati, 2020) }\end{array}$ & - & $\sqrt{ }$ & - & - \\
\hline $\begin{array}{l}\text { (Handoko \& } \\
\text { Rahardjo, 2017) }\end{array}$ & $\sqrt{ }$ & $\sqrt{ }$ & - & - \\
\hline $\begin{array}{l}\text { (Luhur \& Pailan, } \\
\text { 2016) }\end{array}$ & $\sqrt{ }$ & $\sqrt{ }$ & - & $\sqrt{ }$ \\
\hline $\begin{array}{l}\text { (Bangun \& } \\
\text { Saptadi, 2019) }\end{array}$ & $\sqrt{ }$ & $\sqrt{ }$ & - & - \\
\hline $\begin{array}{l}\text { (Wulandari, } \\
\text { 2017) }\end{array}$ & $\sqrt{ }$ & $\sqrt{ }$ & - & $\sqrt{ }$ \\
\hline
\end{tabular}

\begin{tabular}{|c|c|c|c|c|}
\hline \multirow{2}{*}{ Paper Identity } & \multicolumn{4}{|c|}{ Klasifikasi Bahaya } \\
\hline & Kimia & Fisika & Biologi & Ergo \\
\hline $\begin{array}{l}\text { (Novita \& } \\
\text { Nawawinetu, } \\
\text { 2018) }\end{array}$ & - & $\sqrt{ }$ & - & - \\
\hline $\begin{array}{l}\text { (AL Bantani et } \\
\text { al., 2015) }\end{array}$ & $\sqrt{ }$ & $\sqrt{ }$ & - & $\sqrt{ }$ \\
\hline (Darmaji, 2019) & $\sqrt{ }$ & $\sqrt{ }$ & - & - \\
\hline $\begin{array}{l}\text { (Nurfauzan \& } \\
\text { Thaib, 2018) }\end{array}$ & $\sqrt{ }$ & $\sqrt{ }$ & - & $\sqrt{ }$ \\
\hline (Rini, 2017) & - & $\sqrt{ }$ & - & - \\
\hline $\begin{array}{l}\text { (Loandi \& } \\
\text { Widiawan, } \\
\text { 2018) }\end{array}$ & - & $\sqrt{ }$ & - & - \\
\hline $\begin{array}{l}\text { (Alfatiyah, } \\
\text { 2017) }\end{array}$ & $\sqrt{ }$ & $\sqrt{ }$ & - & - \\
\hline $\begin{array}{l}\text { (Marbun et al., } \\
\text { 2015) }\end{array}$ & $\sqrt{ }$ & $\sqrt{ }$ & - & - \\
\hline $\begin{array}{l}\text { (Pertiwi et al., } \\
\text { 2015) }\end{array}$ & $\sqrt{ }$ & $\sqrt{ }$ & - & - \\
\hline
\end{tabular}

Daftar artikel yang terpilih kemudian dianalisis dari aspek penilaian risiko seperti yang di tunjukan pada tabel 2 berikut

\section{Tabel 2. Hasil Analisis Penilaian Risiko Dalam Industri Manufaktur di Indonesia}

\begin{tabular}{|c|c|c|c|c|}
\hline \multirow[b]{2}{*}{ Paper Identity } & \multicolumn{4}{|c|}{ Penilaian Risiko } \\
\hline & $\begin{array}{l}\text { Very } \\
\text { High }\end{array}$ & High & Medium & Low \\
\hline $\begin{array}{l}\text { (Nuryono \& Aini, } \\
\text { 2020) }\end{array}$ & $\sqrt{ }$ & $\sqrt{ }$ & $\sqrt{ }$ & - \\
\hline $\begin{array}{l}\text { (Giananta et al., } \\
\text { 2020) }\end{array}$ & - & $\sqrt{ }$ & $\sqrt{ }$ & $\sqrt{ }$ \\
\hline $\begin{array}{l}\text { (Tiara \& Herry, } \\
2020)\end{array}$ & $\sqrt{ }$ & $\sqrt{ }$ & $\sqrt{ }$ & $\sqrt{ }$ \\
\hline $\begin{array}{l}\text { (Mirawati et al., } \\
\text { 2017) }\end{array}$ & $\sqrt{ }$ & $\sqrt{ }$ & $\sqrt{ }$ & $\sqrt{ }$ \\
\hline $\begin{array}{l}\text { (Ningsih \& Hati, } \\
\text { 2019) }\end{array}$ & - & $\sqrt{ }$ & $\sqrt{ }$ & - \\
\hline (Ilmi, 2019) & $\sqrt{ }$ & $\sqrt{ }$ & $\sqrt{ }$ & $\sqrt{ }$ \\
\hline (Saputro, 2019) & $\sqrt{ }$ & $\sqrt{ }$ & $\sqrt{ }$ & $\sqrt{ }$ \\
\hline $\begin{array}{l}\text { (Restuputri Palupi } \\
\text { \& Dyah Sari, 2015) }\end{array}$ & $\sqrt{ }$ & $\sqrt{ }$ & $\sqrt{ }$ & $\sqrt{ }$ \\
\hline $\begin{array}{l}\text { (Khasanah \& } \\
\text { Nawawinetu, 2018) }\end{array}$ & - & $\sqrt{ }$ & $\sqrt{ }$ & $\sqrt{ }$ \\
\hline $\begin{array}{l}\text { (Santoso et al., } \\
\text { 2016) }\end{array}$ & $\sqrt{ }$ & $\sqrt{ }$ & $\sqrt{ }$ & $\sqrt{ }$ \\
\hline (Sutrisno, 2020) & - & $\sqrt{ }$ & - & - \\
\hline $\begin{array}{l}\text { (Fauzan } \& \\
\text { Puspitasari, 2019) }\end{array}$ & - & $\sqrt{ }$ & $\sqrt{ }$ & $\sqrt{ }$ \\
\hline
\end{tabular}


ISSN 2623-1573 (Print)

\begin{tabular}{|c|c|c|c|c|}
\hline \multirow[b]{2}{*}{ Paper Identity } & \multicolumn{4}{|c|}{ Penilaian Risiko } \\
\hline & $\begin{array}{l}\text { Very } \\
\text { High }\end{array}$ & High & Medium & Low \\
\hline $\begin{array}{ll}\text { (Ramadanita } & \& \\
\text { Rusmiati, 2020) } & \end{array}$ & $\sqrt{ }$ & $\sqrt{ }$ & $\sqrt{ }$ & $\sqrt{ }$ \\
\hline $\begin{array}{ll}\text { (Handoko } & \& \\
\text { Rahardjo, 2017) } & \end{array}$ & $\sqrt{ }$ & $\sqrt{ }$ & $\sqrt{ }$ & $\sqrt{ }$ \\
\hline $\begin{array}{l}\text { (Luhur \& Pailan, } \\
\text { 2016) }\end{array}$ & - & - & - & - \\
\hline $\begin{array}{l}\text { (Bangun \& Saptadi, } \\
\text { 2019) }\end{array}$ & $\sqrt{ }$ & $\sqrt{ }$ & $\sqrt{ }$ & $\sqrt{ }$ \\
\hline (Wulandari, 2017) & - & $\sqrt{ }$ & $\sqrt{ }$ & $\sqrt{ }$ \\
\hline $\begin{array}{l}\text { (Novita \& } \\
\text { Nawawinetu, 2018) }\end{array}$ & - & $\sqrt{ }$ & $\sqrt{ }$ & - \\
\hline $\begin{array}{l}\text { (AL Bantani et al., } \\
\text { 2015) }\end{array}$ & - & $\sqrt{ }$ & $\sqrt{ }$ & $\sqrt{ }$ \\
\hline (Darmaji, 2019) & - & - & - & - \\
\hline $\begin{array}{l}\text { (Nurfauzan } \\
\text { Thaib, 2018) }\end{array}$ & $\sqrt{ }$ & $\sqrt{ }$ & $\sqrt{ }$ & $\sqrt{ }$ \\
\hline (Rini, 2017) & - & $\sqrt{ }$ & $\sqrt{ }$ & $\sqrt{ }$ \\
\hline $\begin{array}{ll}\text { (Loandi } \& \\
\text { Widiawan, 2018) }\end{array}$ & - & $\sqrt{ }$ & $\sqrt{ }$ & $\sqrt{ }$ \\
\hline (Alfatiyah, 2017) & - & - & $\sqrt{ }$ & $\sqrt{ }$ \\
\hline $\begin{array}{l}\text { (Marbun et al., } \\
\text { 2015) }\end{array}$ & - & $\sqrt{ }$ & $\sqrt{ }$ & $\sqrt{ }$ \\
\hline (Pertiwi et al., 2015) & - & - & - & - \\
\hline
\end{tabular}

Daftar artikel yang terpilih kemudian dianalisis dari aspek pengendalian bahaya seperti yang di tunjukan pada tabel 03 berikut

Tabel 3. Hasil Analisis Pengendalian Bahaya Dalam Industri Manufaktur di Indonesia

\begin{tabular}{|c|c|c|c|c|c|}
\hline \multirow{2}{*}{$\begin{array}{c}\text { Paper } \\
\text { Identity }\end{array}$} & \multicolumn{5}{|c|}{ Pengendalian Risiko } \\
\hline & Elim & Sub & Eng & Adm & APD \\
\hline $\begin{array}{l}\text { (Nuryono \& } \\
\text { Aini, 2020) }\end{array}$ & - & $\sqrt{ }$ & $\sqrt{ }$ & $\sqrt{ }$ & $\sqrt{ }$ \\
\hline $\begin{array}{l}\text { (Giananta et } \\
\text { al., 2020) }\end{array}$ & - & - & $\sqrt{ }$ & $\sqrt{ }$ & $\sqrt{ }$ \\
\hline $\begin{array}{lr}\text { (Tiara } \& \\
\text { Herry, 2020) }\end{array}$ & - & - & - & - & - \\
\hline $\begin{array}{l}\text { (Mirawati et } \\
\text { al., 2017) }\end{array}$ & - & - & $\sqrt{ }$ & $\sqrt{ }$ & $\sqrt{ }$ \\
\hline $\begin{array}{l}\text { (Ningsih \& } \\
\text { Hati, 2019) }\end{array}$ & - & - & - & - & - \\
\hline (Ilmi, 2019) & - & - & - & $\sqrt{ }$ & $\sqrt{ }$ \\
\hline $\begin{array}{l}\text { (Saputro, } \\
\text { 2019) }\end{array}$ & - & - & $\sqrt{ }$ & $\sqrt{ }$ & $\sqrt{ }$ \\
\hline \begin{tabular}{lr}
\multicolumn{2}{l}{ Restuputri } \\
Palupi \\
Dyah \\
$2015)$
\end{tabular} & - & - & $\sqrt{ }$ & $\sqrt{ }$ & $\sqrt{ }$ \\
\hline
\end{tabular}

\begin{tabular}{|c|c|c|c|c|c|}
\hline \multirow{2}{*}{$\begin{array}{l}\text { Paper } \\
\text { Identity }\end{array}$} & \multicolumn{5}{|c|}{ Pengendalian Risiko } \\
\hline & Elim & Sub & Eng & Adm & APD \\
\hline $\begin{array}{l}\text { (Khasanah \& } \\
\text { Nawawinetu, } \\
\text { 2018) }\end{array}$ & - & - & - & $\sqrt{ }$ & $\sqrt{ }$ \\
\hline $\begin{array}{ll}\text { (Santoso et } \\
\text { al., 2016) }\end{array}$ & - & - & - & $\sqrt{ }$ & $\sqrt{ }$ \\
\hline $\begin{array}{l}\text { (Sutrisno, } \\
\text { 2020) }\end{array}$ & - & - & $\sqrt{ }$ & $\sqrt{ }$ & - \\
\hline $\begin{array}{l}\text { (Fauzan \& } \\
\text { Puspitasari, } \\
\text { 2019) }\end{array}$ & - & - & $\sqrt{ }$ & $\sqrt{ }$ & $\sqrt{ }$ \\
\hline $\begin{array}{l}\text { (Ramadanita } \\
\& \text { Rusmiati, } \\
\text { 2020) }\end{array}$ & $\sqrt{ }$ & $\sqrt{ }$ & $\sqrt{ }$ & $\sqrt{ }$ & $\sqrt{ }$ \\
\hline $\begin{array}{l}\text { (Handoko \& } \\
\text { Rahardjo, } \\
\text { 2017) }\end{array}$ & - & - & - & $\sqrt{ }$ & $\sqrt{ }$ \\
\hline $\begin{array}{l}\text { (Luhur \& } \\
\text { Pailan, 2016) }\end{array}$ & - & - & $\sqrt{ }$ & $\sqrt{ }$ & $\sqrt{ }$ \\
\hline $\begin{array}{l}\text { (Bangun \& } \\
\text { Saptadi, } \\
\text { 2019) }\end{array}$ & - & - & - & $\sqrt{ }$ & $\sqrt{ }$ \\
\hline $\begin{array}{l}\text { (Wulandari, } \\
\text { 2017) }\end{array}$ & - & - & - & $\sqrt{ }$ & $\sqrt{ }$ \\
\hline $\begin{array}{l}\text { (Novita \& } \\
\text { Nawawinetu, } \\
2018 \text { ) }\end{array}$ & - & - & - & $\sqrt{ }$ & $\sqrt{ }$ \\
\hline $\begin{array}{l}\text { (AL Bantani } \\
\text { et al., 2015) }\end{array}$ & - & - & - & $\sqrt{ }$ & $\sqrt{ }$ \\
\hline $\begin{array}{l}\text { (Darmaji, } \\
\text { 2019) }\end{array}$ & - & - & - & $\sqrt{ }$ & $\sqrt{ }$ \\
\hline $\begin{array}{l}\text { (Nurfauzan } \\
\& \quad \text { Thaib, } \\
2018 \text { ) }\end{array}$ & - & - & $\sqrt{ }$ & $\sqrt{ }$ & $\sqrt{ }$ \\
\hline (Rini, 2017) & - & - & $\sqrt{ }$ & $\sqrt{ }$ & $\sqrt{ }$ \\
\hline $\begin{array}{l}\text { (Loandi \& } \\
\text { Widiawan, } \\
\text { 2018) }\end{array}$ & - & - & - & $\sqrt{ }$ & $\sqrt{ }$ \\
\hline $\begin{array}{l}\text { (Alfatiyah, } \\
\text { 2017) }\end{array}$ & - & - & - & $\sqrt{ }$ & $\sqrt{ }$ \\
\hline $\begin{array}{ll}\text { (Marbun et } \\
\text { al., 2015) }\end{array}$ & $\sqrt{ }$ & - & - & $\sqrt{ }$ & $\sqrt{ }$ \\
\hline $\begin{array}{ll}\text { (Pertiwi et } \\
\text { al., 2015) }\end{array}$ & - & - & - & $\sqrt{ }$ & $\sqrt{ }$ \\
\hline
\end{tabular}

\section{PEMBAHASAN}

\section{Identifikasi Bahaya}

Menurut (Gunawan, 2013) bahaya atau hazard merupakan suatu ciri yang dikandung seseuatu (biasanya berbentuk energi) yang memiliki potensi untuk menyebabkan cedera pada manusia atau kerusakan pada harta benda maupun lingkungan alam. Dan secara umum bahaya 
dikelompokkan menjadi bahaya kimia, bahaya fisik (termasuk mekanis, listrik \& gravitasi), bahaya biologi serta bahaya ergonomi (Gunawan, 2013). Identifikasi bahaya adalah upaya sistematis untuk mengetahui adanya bahaya dalam aktivitas organisasi dan identifikasi bahaya ini merupakan langkah awal dalam mengembangkan manajemen risiko keselamatan dan kesehatan kerja (Ilmi, 2019). Dan menurut (Veronica et al., 2014), Identifikasi bahaya adalah identifikasi atas sesuatu yang dapat menyebabkan cedera pada manusia atau kerusakan pada alat atau lingkungan.

Dari jurnal-jurnal yang diperoleh dan di review di dapatkan bahaya yang paling banyak muncul dalam industri manufaktur adalah bahaya fisika (tercatat dari 26 jurnal diperoleh 26 jurnal yang mengidentifikasi adanya bahaya fisik), dilanjutkan dengan bahaya kimia (tercatat dari 26 jurnal diperoleht 19 jurnal yang mengidentifikasi adanya bahaya kimia), bahaya ergonomi (tercatat dari 26 jurnal diperoleh 6 jurnal yang mengidentifikasi adanya bahaya ergonimi), dan untuk bahaya biologi teratat dari 26 jurnal tidak ada jurnal yang mengidentifikasi adanya bahaya biologi.

Beberapa gambaran terkait bahaya fisika dari beberapa industri manufaktur, dalam penelitian (Nuryono \& Aini, 2020), menjelaskan dalam industri manufaktur pengolahan teh teridentifikasi bahaya fisika pada proses blending yaitu pisau pemisah cup yang berisiko tergores pisau pemisah cup dalam aktifitas memasukan cup ke dalam pengisian cup dan pada proses filling yaitu terkena mesin press dalam aktifitas pengambilan sample untuk QC.

Dalam penelitian (Giananta et al., 2020), menjelaskan dalam industri manufaktur yang memproduksi mesin tepat guna mengidentifikasi bahaya fisika dari setiap stasiun kerja meliputi pada stasiun cutting dan stasiun electricity bahaya fisika yang teridentifikasi yaitu terkena mata pisau, terkena mesin gerinda potong, pada stasiun machining tersayat mesin pencacah, terkena mesin gerinda dan terjepit mesin produksi dan pada stasiun finishing yaitu terkena mesin gerinda.

Dari penjabaran diatas terkait identifikasi bahaya ada berbagai metode yang dapat digunakan untuk melakukan identifikasi bahaya, dalam penelitian (Nuryono \& Aini, 2020), metode identifikasi bahaya dapat dilakukan dengan cara yaitu pertama dengan observasi atau inspeksi terencana, observasi terhadap kondisi fakta tempat kerja, peralatan dan sebagainya atau inspeksi terencana yang lebih fokus terhadap bahaya tertentu dengan menggunakan lembar pemeriksaan dan indeks dan kedua yaitu brainstorming, dimana untuk proses yang belum diakukan atau berdasarkan pertimbanan seperti jarak yang jauh sehingga sulit dilakukan observasi atau inpeksi maka identifikasi dapat dilakukan melalui brainstorming. Dan terdapat beberapa teknik dalam mengidentifikasi bahaya diantaranya job safety analysis, what-if analysis, hazard and operability studies, fault tree analysis dan failure mode and effect analysis dan HIRA (Nuryono \& Aini, 2020).

\section{Penilaian Risiko}

Setelah dilakukannya identifikasi bahaya dilanjutkan dengan penilaian risiko yang bertujuan untuk mengevaluasi besarnya risiko serta skenario dampak yang akan ditimbulkan dari suatu bahaya dan penilaian risiko ini digunakan sebagai langkah saringan untuk menentukan tingkat risiko ditinjau dari kemungkinan kejadian dan keparahan yang dapat ditimbulkan (Sahid, 2019). Penilaian potensi bahaya yang diidentifikasi bahaya risiko melalui analisa dan perhitungan risiko yang dimaksudkan untuk menentukan besarnya risiko dengan mempertimbangkan kemungkinan terjadi dan tingkat keparahan atau besar akibat yang ditimbulkan (Ilmi, 2019). Dari hasil analisa dan perhitungan dapat diditentukan peringkat nilai risiko sehingga dapat di lakukan penilaian risiko yang memiliki dampak penting terhadap perusahaan (Ilmi, 2019). 
Dari jurnal-jurnal yang diperoleh dan di review di dapatkan dari hasil penilaian risiko dimana tingkat risiko yang paling banyak muncul dalam industri manufaktur adalah pada level medium \& high (dari 26 jurnal terdapat 22 jurnal yang menilai risiko pada level risiko medium dan high), dilanjutkan pada level low (dari 26 jurnal terdapat 19 jurnal yang menilai risiko pada level risiko low), dan yang terakhir pada level very high (dari 26 jurnal terdapat 11 jurnal yang menilai risiko pada level risiko very high).

Gambaran terkait tingkat risiko di beberapa manufaktur sebagai berikut, dalam penelitian (Ilmi, 2019), penilaian risiko pada level very high pada aktivitas penggerindaan yang berisiko kulit terluka/sobek terkena pecahan cakram dengan likelihood unlikely dan severity moderate dan didapatnya risk rating very high, penilaian risiko pada level high pada aktivitas memotong/tekuk besi dengan mesin yang berisiko tangan terpotong mesin alat potong tekuk dengan likelihood very unlikely dan severity extreme dan didapatnya risk rating high, penilaian risiko pada level medium pada aktivitas pengovenan yang berisiko kulit terbakar, iritasi kulit dengan likelihood unlikely dan severity moderate dan didapatnya risk rating medium, dan penilaian risiko pada level low pada aktivitas assembly berisiko jari tangan terjepit diantara part besi dengan likelihood very likely dan severity slight dan didapatnya risk rating low.

Dan dalam penilaian risiko ini sebaiknya dilakukan dengan melibatkan beberapa orang (berkelompok) seperti pekerja yang bekerja secara langsung, pengawas, petugas pengelola keselamatan, dan orang-orang lain yang terkait karena keahlian atau pekerjaan terhadap risiko yang akan dikaji dan penilaian risiko dapat dilakukan secara kualitatif, semi kuantitatif, maupun kuantitatif (Nuryono \& Aini, 2020).

\section{Pengendalian Risiko}

Pengendalian risiko merupakan cara untuk mengatasi potensi bahaya yang terdapat dalam lingkungan kerja. Potensi bahaya tersebut dapat dikendalikan dengan menentukan suatu skala prioritas terlebih dahulu yang kemudian dapat membantu dalam prioritas terlebih dahulu yang kemudian dapat membantu dalam pemilihan pengendalian resiko yang disebut hirarki pengendalian resiko (Mirawati et al., 2017). Dalam menentukan langkah-langkah pengendalian maka konsep yang harus dipahami adalah hirarki pengendalian sehingga pengendalian yang dilakukan berlangsung efektif. (Markkanen, 2004). Pengendalian yang banyak dijumpai dalam buku-buku keselamatan dan kesehatan kerja adalah eliminasi, substitusi, engineering control, administrative control dan alat pelindung diri (Mirawati et al., 2017).

Dari jurnal-jurnal yang diperoleh dan di review di dapatkan dari hasil pengendalian bahaya \& risiko yang paling banyak digunakan dalam industri manufaktur adalah pada pengendalian administratif sebagai urutan pertama (tercatat dari 26 jurnal diperoleh 24 jurnal yang melaksanakan pengendalian administratif), pengendalian alat pelindung diri urutafn kedua (tercatat dari 26 jurnal diperoleh 23 jurnal yang melaksanakan pengendalian alat pelindung diri), pengendalian engineering urutan ketiga (tercatat dari 26 jurnal diperoleh 11 jurnal yang melaksanakan pengendalian engineering), dan pengendalian substitusi dan eliminasi urutan keempat dan kelimat (tercatat dari 26 jurnal diperoleh masing-masing 2 jurnal yang melaksanakan pengendalian substitusi dan eliminasi).

Gambaran terkait pengendalian di beberapa manufaktur sebagai berikut, dalam penelitian (Marbun et al., 2015) pengendalian eliminasi yang dilakukan terhadap risiko cidera punggung karena kejatuhan material yaitu dengan mengurangi berat material yang diangkat. Dalam penelitian (Nuryono \& Aini, 2020) pengendalian substitusi yang dilakukan terhadap risiko tergores bagian tajam pada proses blending yaitu dengan mengganti cutter dengan gunting. Dalam (Saputro, 2019), pengendalian engineering yang dilakukan yaitu dengan dengan 
memperbaiki dan menambahkan pengamanan pada mesin-mesin produksi. Dalam penelitian (Ilmi, 2019) pengendalian administratif yang dilakukan pada aktifitas memotong/tekuk besi dengan mesin yaitu dengan dengan memberikan lembar SOP dan memberikan bimbingan dalam operasi dan pengendalian alat pelindung diri yang dilakukan pada aktifitas pengelasan yaitu dengan meamstikan operator menggunakan alat pelindung diri lengkap saat bekerja.

\section{KESIMPULAN}

Kesimpulan dari literature review ini terkait manajemen risiko keselamatan dan kesehatan kerja pada industri manufaktur adalah dalam identifikasi bahaya pada industri manufaktur, bahaya yang paling banyak terdentifikasi yaitu bahaya fisika, dalam penilaian risiko pada industri manufaktur di dapatkan tingkat risiko yang paling banyak muncul adalah pada level medium \& high dan dalam pengendalin bahaya dan risiko pada industri manufaktur, di dapatkan hasil pengendalian bahaya \& risiko yang paling banyak digunakan adalah pada pengendalian administratif

\section{UCAPAN TERIMAKASIH}

Peneliti mengucapkan terima kasih kepada Allah SWT, orang tua, keluarga dan dosen pembimbing akademik yang selama ini telah membantu peneliti dalam menyelesaikan penelitian ini.

\section{DAFTAR PUSTAKA}

AL Bantani, A. S., Herlina, L., \& Mariawati, A. S. (2015). Identifikasi Potensi Bahaya Dengan Menggunakan Metode Job Safety Analysis (JSA) (Studi Kasus di PT XYZ).

Alfatiyah, R. (2017). Analisis Manajemen Risiko Keselamatan dan Kesehatan Kerja dengan Menggunakan Metode HIRARC pada Pekerja Seksi Casting. Jurnal Mesin Teknologi (SINTEK Jurnal), 11(2), 88-101.

Bangun, E. S., \& Saptadi, S. (2019).
Kecelakaan Kerja Dengan Metode Job Safety Analysis Pada Divisi Foundry PT . Austenite Foundry Medan. 1-6.

Darmaji, M. (2019). Evaluasi Potensi Bahaya Keselamatan Dan Kesehatan Kerja (K3) Pada PT. Mmi - Gresik. JISO : Journal of Industrial and Systems Optimization, 2, 94-103. https://doi.org/10.51804/jiso.v2i2. 94-103

Fauzan, R., \& Puspitasari, N. B. (2019). Evaluasi Bahaya Kerja Menggunakan Metode Hazard Identification Risk Assesment and Risk Control Dalam Memproduksi Rak Engine Overhoul Pada CV.MANSGROUP. 1-8.

Giananta, P., Hutabarat, J., \& Soemanto. (2020). Analisa Potensi Bahaya Dan Perbaikan Sistem Keselamatan dan Kesehatan Kerja Menggunakan Metode HIRARC di PT. Boma bisma indra. 3(2), 106110.

Gunawan, F. . (2013). Safety Leadership: Building Excellent Operation (pertama). PT.Dian Rakyat.

Handoko, J. C., \& Rahardjo, J. (2017). Perancangan Hazard Identification, Risk Assessment, And Determining Control ( HIRADC ) Di Schneider Electric Cikarang. 5(2), 159-164.

Ilmi, R. F. (2019). Manajemen Risiko Kesehatan dan Keselamatan Kerja Dengan Penyusunan Hazard Identification Risk Assessment and Risk Control (HIRARC) (Studi Kasus: PT Entri Jaya Makmur). Rabit: Jurnal Teknologi Dan Sistem Informasi Univrab, 1(1), 2019.

Khasanah, E. M. I., \& Nawawinetu, E. D. (2018). Hazads Identification and Risk Assessment of Operational in PT Sinar Indogreen Kencana AAC Production Area's. Journal of Vocational Health Studies, 01, 20- 
27.

https://doi.org/10.20473/jvhs.V2I1 .2018.20-27

Loandi, B. S., \& Widiawan, K. (2018). Hazard identification , Risk Assessment and Risk control ( HIRARC ) di PT . Teno Indonesia. 6(2), 279-284.

Luhur, B. A., \& Pailan. (2016). Evaluasi Keselamatan Kerja Dengan Menggunakan Metode Hazards Identification, Risk Assessment and Risk Control(HIRARC). Kesehatan Masyarakat, 137-147.

Mangkunegara, A. A. . (2016). Manajemen sumber daya manusia perusahaan. PT. Remaja Rosdakarya.

Marbun, R. J., Puspitasari, N. B., \& Budiawan, W. (2015). Identifikasi dan Analisis Risiko Keselamatan dan Kesehatan Kerja Pada Area Produksi PT. Pelita Cengkareng Paper.

Markkanen, P. K. (2004). Occupational safety and health in Indonesia= Keselamatan dan kesehatan kerja di Indonesia. International Labour Organization.

Mirawati, A., Anindita, G., \& Rachmad, A. N. (2017). Identifikasi Bahaya Pada Section Marking Cutting Dan Shotblasting Process Di Perusahaan Manufaktur Dengan Metode HIRARC. Proceeding 2nd Conference On Safety Engineering, 2581, 611-616.

Ningsih, S. O. D., \& Hati, S. W. (2019). Analisis Resiko Keselamatan Dan Kesehatan Kerja (K3) Dengan Menggunakan Metode Hazard and Operability Study (Hazop) Pada Bagian Hydrotest Manual Di Pt. Cladtek Bi Metal Manufacturing. Journal of Applied Business Administration, 3(1), 29-39. https://doi.org/10.30871/jaba.v3i1. 1288

Novita, L., \& Nawawinetu, E. D. (2018). Risk Assessment Pengoperasian Overhead Crane (OHC) Double
Girder Di Divisi Kapal Niaga Di PT. PAL Indonesia (Persero). Journal of Vocational Health Studies, $\quad 01$, 1-7. https://doi.org/10.20473/jvhs.V2I1 .2018.1-7

Nurfauzan, R. A., \& Thaib, D. (2018). Gambaran Tingkat Risiko Kesehatan Dan Keselamatan Kerja Pada Bagian Produksi I Di Pt . " X " Menggunakan Metode Hazard Identification , Risk Assessment and Risk Control ( Hirarc ) Tahun 2018. Environmental Occupational Health and Safety Journal, 1(1), 61-70.

Nuryono, A., \& Aini, M. N. (2020). Analisis Bahaya dan Resiko Kerja di Industri Pengolahan Teh dengan Metode HIRA atau IBPR. Journal of Industrial and Engineering System, 1(1), 65-74. https://doi.org/10.31599/jies.v1i1. 166

Pertiwi, A. D., Sugiono, \& Efranto, R. Y. (2015). Implementasi Job Safety Analysis ( Jsa ) Dalam Upaya Pencegahan Terjadinya Kecelakaan Akibat Kerja ( Studi Kasus : Pt . Adi Putro Wirasejati ) Implementation Of Job Safety Analysis ( Jsa ) In Prevention Of Work Accide. Rekayasa Dan Menejamen Sistem Industri, 3(2), 386-396.

Ramadanita, F., \& Rusmiati, E. (2020). Upaya Penurunan Angka Risiko Kecelakaan Kerja Metode Hirarc Di Pt Astanita Sukses Apindo. 18(2), 32-39.

Restuputri Palupi, D., \& Dyah Sari, R. P. (2015). Analisis Kecelakaan Kerja Dengan Menggunakan Metode Hazard and Operability Study ( Hazop ). Jurnal Ilmiah Teknik Industri, 14(1), 24-35.

Rini, W. D. S. (2017). Evaluasi Penerapan Sarana Pengendalian Risiko di Bagian Produksi Tiang Pancang Bulat PT.TB.PBB Wijaya Karya 
Beton Boyolali. Occupational Medicine, 53(4), 130.

Sahid, M. N. (2019). Manajemen Bahaya Dan Risiko Pada Pekerja Gondola Proyek Apartemen Menara One. Jurnal Neo Teknika, Vol.5 No.1 Juni 2019, 8(5), 55.

Santoso, R. I., Parwati, C. I., \& Yusuf, M. (2016). Analisis Sistem Manajemen Keselamatan dan Kesehatan Kerja (SMK3) Dengan Pendekatan Faktor Kesalahan Manusia di PT. Khalifah Niaga Lantabura. Jurnal REKAVASI, 4(2), 60-118.

Saputro, P. B. (2019). Analisis Identifikasi Potensi Bahaya Dalam Upaya Pencegahan Kecelakaan Kerja Dengan Metode Job Safety Analysis Pada Proses Produksi Di PT Infoglobal Teknologi Semesta. 08, 17-26.

Sutrisno, T. (2020). Manajemen Risiko Proses Manufaktur Dengan Mesin Perkakas Dan Produksi Konvesional Dan Peluang Penurunan Risiko Bahaya (Reduction Risk) Dengan Penerapan Teknologi Industri 4.0 (Studi Kasus: PT PINDAD (PERSERO) Bandung). 0, 1-3.

Sutriyanto, E. (2021, February 25). Tekanan Jumlah Kecelakaan Kerja, Industri Manufaktur Indonesia Didorong Gunakan Robot. Www.Tribunnews.Com. https://www.tribunnews.com/bisni s/2021/02/25/tekan-jumlahkecelakaan-kerja-industrimanufaktur-indonesia-didoronggunakan-robot?page=all

Tiara, \& Herry. (2020). Higeia Journal of Public Health. Higeia Journal of Public Health Research and Development, 1(3), 84-94.

Veronica, S., Ruminta, R., \& Nugroho, S. (2014). Analisis Risiko Keselamatan dan Kesehatan Kerja Dengan Menggunakan Pendekatan HIRARC. Teknik Industri UNDIP.
Wulandari, Y. R. (2017). Penerapan HIRARC sebagai upaya Pencegahan Kecelakaan Kerja pada Proses Produksi Garmen. Higeia Journal of Public Health Research and Development, 1(3), 84-94. 